\title{
Early warning indicators for mesophilic anaerobic digestion of corn stalk: a combined experimental and simulation approach
}

\author{
Yiran Wu' ${ }^{1}$, Adam Kovalovszki ${ }^{2}$, Jiahao Pan ${ }^{1}$, Cong Lin ${ }^{1}$, Hongbin Liu ${ }^{3}$, Na Duan ${ }^{1 *}$ and Irini Angelidaki ${ }^{2}$
}

\begin{abstract}
Background: Monitoring and providing early warning are essential operations in the anaerobic digestion (AD) process. However, there are still several challenges for identifying the early warning indicators and their thresholds. One particular challenge is that proposed strategies are only valid under certain conditions. Another is the feasibility and universality of the detailed threshold values obtained from different AD systems. In this article, we report a novel strategy for identifying early warning indicators and defining threshold values via a combined experimental and simulation approach.

Results: The AD of corn stalk (CS) was conducted using mesophilic, completely stirred anaerobic reactors. Two overload modes (organic and hydraulic) and overload types (sudden and gradual) were applied in order to identify early warning indicators of the process and determine their threshold values. To verify the selection of experimental indicators, a combined experimental and simulation approach was adopted, using a modified anaerobic bioconversion mathematical model (BioModel). Results revealed that the model simulations agreed well with the experimental data. Furthermore, the ratio of intermediate alkalinity to bicarbonate alkalinity (IA/BA) and volatile fatty acids (VFAs) were selected as the most potent early warning indicators, with warning times of 7 days and 5-8 days, respectively. In addition, IA, BA, and VFA/BA were identified as potential auxiliary indicators for diagnosing imbalances in the AD system. The relative variations for indicators based on that of steady state were observed instead of the absolute threshold values, which make the early warning more feasible and universal.
\end{abstract}

Conclusion: The strategy of a combined approach presented that the model is promising tool for selecting and monitoring early warning indicators in various corn stalk AD scenarios. This study may offer insight into industrial application of early warning in AD system with mathematical model.

Keywords: Corn stalk, Anaerobic digestion, Early warning, BioModel

\section{Background}

Anaerobic digestion (AD), as an efficient technology for organic waste treatment, has been widely adopted worldwide [1]. Among others, straw has a great potential to serve as a feedstock for anaerobic methane $\left(\mathrm{CH}_{4}\right)$ production, due to its abundance and suitable bioconversion characteristics [2]. In China, straws are produced at a high annual rate of approximately 1 billion metric tons

\footnotetext{
*Correspondence: duanna@cau.edu.cn

${ }^{1}$ College of Water Resources and Civil Engineering, China Agricultural University, Beijing 100083, China

Full list of author information is available at the end of the article
}

[3], and about $30 \%$ of those were underutilized [3, 4]. In addition, the methanogenic potential of some major straws is $2.86-3.78 \times 10^{5} \mathrm{Nm}^{3} \mathrm{CH}_{4} / \mathrm{kg}$ VS [5]. However, straw is consisting of cellulose, hemicellulose, and lignin, which is a typical high carbon-to-nitrogen $(\mathrm{C} / \mathrm{N})$ substrate $[2,6]$. And excessive volatile fatty acids (VFAs), which are intermediates of $\mathrm{AD}$, may be produced when feedstock overloading occurs, especially with high $\mathrm{C} / \mathrm{N}$ (e.g., > 30) [2, 5, 7]. Besides, the complex structure of lignocellulose is difficult for microbial cellulolytic enzymes to access, limiting degradation [8]. Therefore, some previous studies reported that the moderate organic loading 
rates (OLRs) were very vital to avoid system acidification. The thermophilic AD process of straw can only be stably operated under relatively low organic loading rates (OLRs) and below $2 \mathrm{~kg} \mathrm{VS} /\left(\mathrm{m}^{3}\right.$ day) [9]. Meanwhile, $\mathrm{Li}$ et al. [10] suggested that the mesophilic anaerobic codigestion of rice stalk with cow manure should be operated at an OLR of 3-6 kg VS/( $\mathrm{m}^{3}$ day). Ward et al. [11] found that biogas projects using straw as substrate also tend to be controlled at suboptimal OLRs to prevent process inhibition.

Besides optimal operational parameters like OLR, reliable early warning and regulation systems are also favorable for AD process. Previously, many studies have been carried out to explore feasible warning indicators in different AD systems. Some examples for several indicators proposed include VFA concentrations, alkalinity, biogas composition, specific intermediate metabolite (like glycerol, aromatic compound, etc.) concentrations, microbial community composition, and enzyme activity [12-17]. In addition, some coupled indicators, such as the ratio between intermediate and partial alkalinities or VFA concentrations and bicarbonate alkalinity (BA), showed better performance than individual indicators [18]. However, when comparing the results of previous studies, it must be pointed out that the proposed strategies are only valid under certain conditions, as some parameters may have different sensitivities to environmental fluctuations in different AD systems. For instance, Castellano et al. [19] suggested that hydrogen $\left(\mathrm{H}_{2}\right)$ concentrations have a high discriminatory ability for process state identification. On the contrary, Kleyböcker et al. [20] showed that $\mathrm{H}_{2}$ partial pressure was not an ideal indicator, because of its unstable responses under organic overload conditions in an AD system treating rapeseed oil. In addition, the indicator threshold values might vary in $\mathrm{AD}$ systems with different substrates and operating conditions. In a specific case, Pullammanappallil et al. [21] suggested that the critical value of propionic acid was $2750 \mathrm{mg} / \mathrm{L}$, while Holm-Nielsen et al. [22] found it to be $1500 \mathrm{mg} / \mathrm{L}$. Conversely, propionic acid did not show early warning in some trials [20]. Consequently, finding effective indicators and rational threshold values for early warning and inhibition diagnosis is a challenge when working with $\mathrm{AD}$ systems.

Compared with traditional early warning methods, which only monitor process indicators by chemical pathway, modeling the $\mathrm{AD}$ process can provide a flexible and rapid solution for comparing and evaluating large numbers of such indicators, and it provides the possibility of automated warning for industrial applications. Mathematical models have long been used for the simulation of various $\mathrm{AD}$ scenarios, with several computer-aided implementations in existence [23, 24]. Unlike simple models that are mainly used for calculating theoretical biogas and $\mathrm{CH}_{4}$ yields, complex bioconversion models can be used to generate insights about process kinetics, microbial growth inhibition, substrate conversion, and product generation rates, to mention a few of their functionalities. In addition, these models can also handle extensive amounts of numerical data and provide qualitative or quantitative comparisons between the measured and simulated datasets. Hence, using these tools for the evaluation of early warning indicators appears to be a promising approach.

The aims of the present study were therefore to (1) evaluate the reaction of various process parameters during $\mathrm{AD}$ process of corn stalk fed to continuously stirred tank reactors under different overload modes (organic or hydraulic retention time (HRT) overload; and gradual or sudden overload); (2) compare simulation using a proven bioconversion model and experimental results at the same operational conditions; (3) identify and evaluate response parameters that are sufficiently sensitive to environmental disturbances; and (4) define threshold values for the sensitive indicators identified in (3), for the different overload conditions tested.

\section{Results and discussion \\ Digester performance \\ Gaseous parameters}

The $\mathrm{CH}_{4}$ yield and content of the two reactors were seen to have stabilized in the full-load phase, at $0.20 \mathrm{~L} \mathrm{CH}_{4} / \mathrm{g}$ VS $\left(62.20 \%\right.$ of $\left.\mathrm{CH}_{4}\right)$ on average with OLR of $1.50-2.24 \mathrm{~g}$ $\mathrm{VS} /\left(\mathrm{L}\right.$ day) in $\mathrm{R} 1$ and at $0.20 \mathrm{~L} \mathrm{CH}_{4} / \mathrm{g}$ VS $(58.73 \%$ of $\mathrm{CH}_{4}$ ) with OLR between 1.87 and $2.24 \mathrm{~g} \mathrm{VS} /(\mathrm{L}$ day) in R2. During the gradual organic overload phase in R1 (day 101-113), both the $\mathrm{CH}_{4}$ yield and $\mathrm{CH}_{4}$ content decreased significantly to $0.02 \mathrm{~L} \mathrm{CH}_{4} / \mathrm{g}$ VS and $51.76 \%$ on day 113. Regarding the sudden overload phase of $\mathrm{R} 1$, the $\mathrm{CH}_{4}$ yield showed a stepwise rise with elevated OLR, up to $0.37 \mathrm{~L} \mathrm{CH}_{4} / \mathrm{g}$ VS on day 155 with OLR at $3.37 \mathrm{~g} \mathrm{VS} /(\mathrm{L}$ day), and then sharply decreased to $0.12 \mathrm{~L}$ $\mathrm{CH}_{4} / \mathrm{g}$ VS (day 161). With respect to the gradual HRT overload phase of $\mathrm{R} 2$, the $\mathrm{CH}_{4}$ yield showed an acidification response under OLR of 2.81-3.74 g VS/(L day). Subsequently, $\mathrm{CH}_{4}$ production increased slowly and then decreased sharply after day 161 . For each overload condition, the $\mathrm{CH}_{4}$ content decreased slightly in the beginning and then returned to steady-state level (Fig. 1a1, a2). This result was consistent with a previous study, where the $\mathrm{CH}_{4}$ content did not decrease significantly, as long as the $\mathrm{pH}$ was higher than 5.5 [1]; moreover, it reported that raising OLR did not result in a significant change in $\mathrm{CH}_{4}$ content. However, a clear shift in populations of archaea from acetotrophic to hydrogenotrophic methanogenesis may have occurred [25]. 


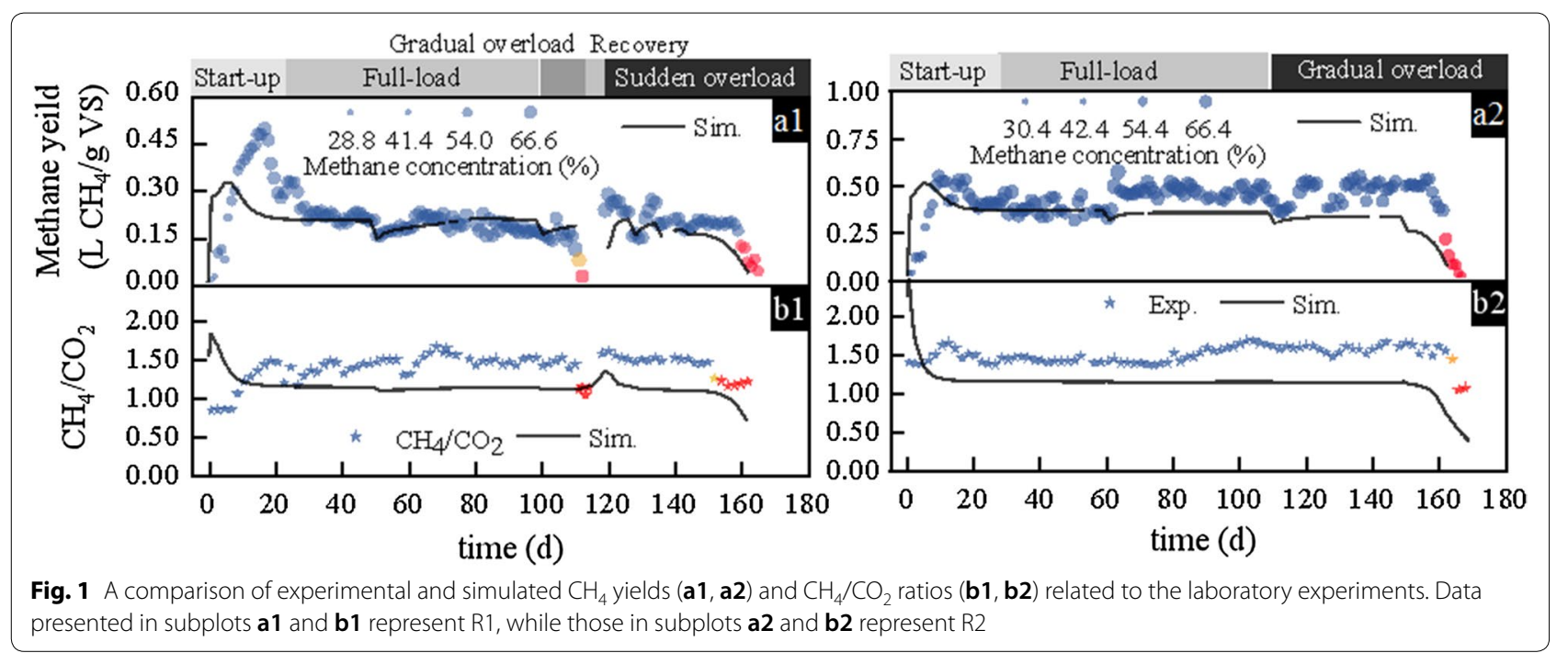

On the other hand, solids evidently accumulated in the reactor, probably due to straw floating and inadequate stirring, which is approximately $5-6 \%$ in the last phase of the experiment (Additional file 1: Fig. S1). Solids accumulated could lead to gas-liquid phase transfer delay and oversaturation of $\mathrm{CH}_{4}$ in the liquid phase [26]. Thereby, above gaseous parameters were relatively insensitive. Meanwhile, the ratio of methane and carbon dioxide $\left(\mathrm{CH}_{4} / \mathrm{CO}_{2}\right)$ showed more intense response to perturbations (Figs. $1 \mathrm{~b}$ and $2 \mathrm{~b}$ ), where sudden drops were

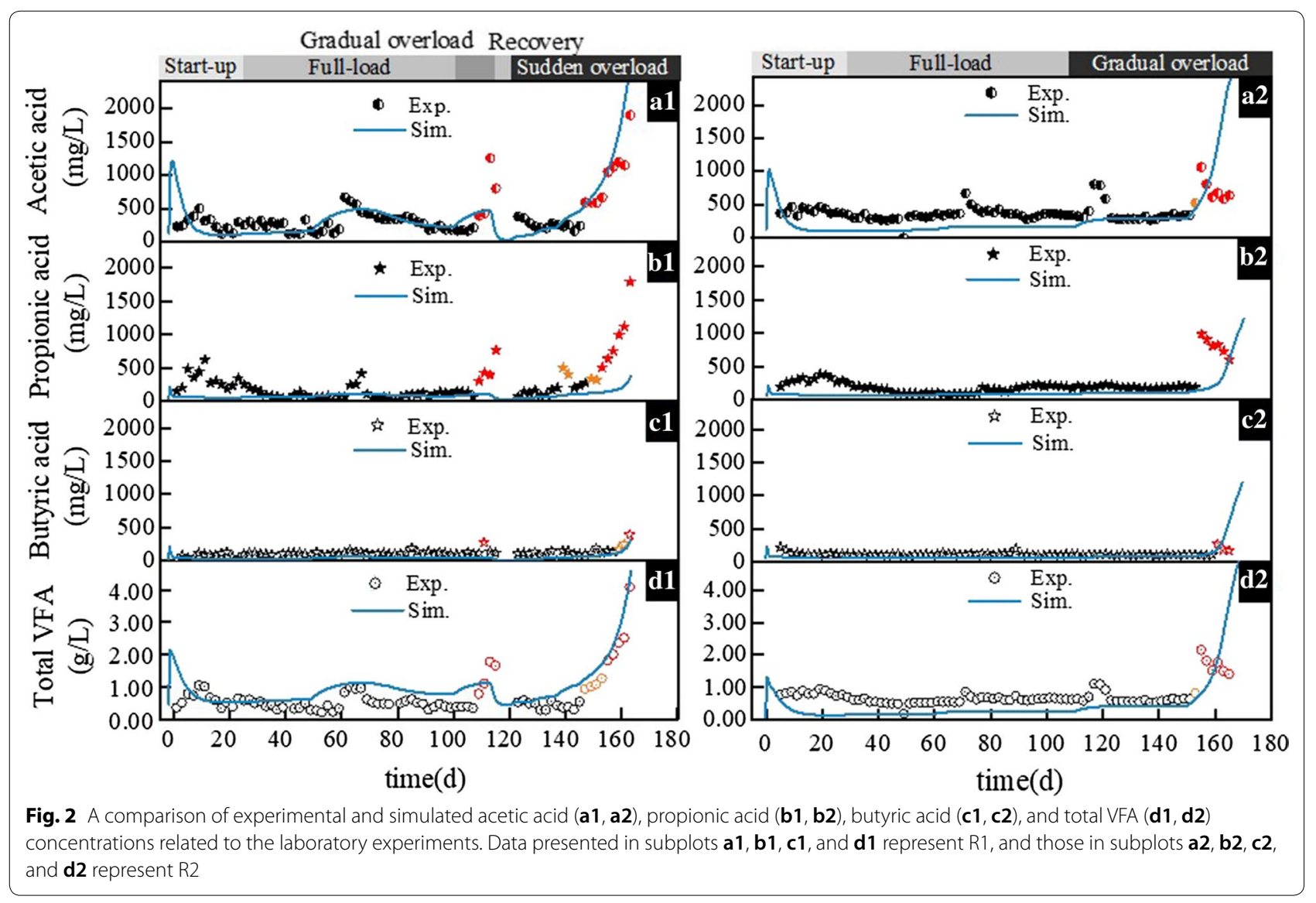


observed on days 112 and 161 in R1, and on day 161 in R2. Further, it realized a remarkable early warning potential in comparison with $\mathrm{CH}_{4}$ yield (8 days earlier) under sudden overload, but barely provided any early warning under gradual overload. Previously, $\mathrm{H}_{2}$ concentration was also suggested as a useful variable for detection of disturbances in both carbohydrate- and protein-based wastewaters [27]. However, in the current study, $\mathrm{H}_{2}$ was only detected in the overload stage on days 112 and 155 in R1, and on day 159 in R2. In addition, these fluctuations were faint and short (1-2 days), with the maximum $\mathrm{H}_{2}$ content of $0.17 \%$ being reached in the sudden overload phase of R1. It is speculated that the $\mathrm{pH}$ and total solid (TS) concentration of the effluent can affect the discrimination of $\mathrm{H}_{2}$.

\section{VFA parameters}

As far as the full-load phase is concerned, the total VFA concentrations of the two reactors were found stable, with average values of $0.49 \mathrm{~g} / \mathrm{L}$ (R1) and $0.60 \mathrm{~g} / \mathrm{L}$ (R2), respectively. However, the total VFA concentration increased rapidly during the overload phase. Acetic acid was the most abundant acid, accounting for approximately $40 \%$ of the total VFA, hence it dominates total VFA concentration changes. Its sharp increase occurred on day 109 (from 0.21 to $0.39 \mathrm{~g} / \mathrm{L}$ ) and day 147 (from 0.23 to $0.59 \mathrm{~g} / \mathrm{L}$ ) in $\mathrm{R} 1$, and on day 155 (from 0.34 to $0.52 \mathrm{~g} / \mathrm{L}$ ) in R2. The sudden rise of total VFA was also occurred on day 109 (from 0.37 to $0.80 \mathrm{~g} / \mathrm{L}$ ) and day 147 (from 0.56 to $0.95 \mathrm{~g} / \mathrm{L}$ ) in $\mathrm{R} 1$, and on day 155 (from 0.82 to $2.15 \mathrm{~g} / \mathrm{L}$ ) in R2. The quick accumulation of acetic acid indicated an imbalance between the acid-forming phase and methaneforming phase of the digestion process, which was in line with the changes seen in $\mathrm{CH}_{4}$ yield and $\mathrm{CH}_{4} / \mathrm{CO}_{2}$ (Fig. 1). Propionic acid concentration was fairly stable during the full-load phase, especially in R2 (Fig. 2c1, c2). Its sharp increase was observed on day 109 (from 0.06 to $0.30 \mathrm{~g} / \mathrm{L}$ ) and day 153 (from 0.32 to $0.50 \mathrm{~g} / \mathrm{L}$ ) in R1, and on day 155 (from 0.18 to $0.98 \mathrm{~g} / \mathrm{L}$ ) in $\mathrm{R} 2$. It is noticeable that in $\mathrm{R} 2$, the sharp increases of VFAs concentration were always followed by the gradual returning to its steady-state concentration, and propionic acid showed the slowest recovery (Fig. 2), which is in agreement with a previous study [22], but different to the finding of Boe et al. [28] stating that acetate revealed recovery while propionate was persistent. In the case of methanogenic populations, possible adaptation to the higher VFA concentrations may have occurred, which was probably the reason for reduced acidification [29]. What's more, a latest research reported that there is a kind of methanogen could uptake acetate but also propionate directly, which might be one of the reasons as well [30]. The findings about slow propionic acid reduction were also supported by the findings from Ahring et al. [31], who showed that propionate acid degraders are the slowest growing and most sensitive VFA-degrading microorganisms in the AD process.

\section{$\mathrm{pH}$, alkalinity, and VFA/BA}

During the full-load period of the experiment, $\mathrm{pH}$ values ranged from 6.77 to 6.90 (R1) and 6.67 to 6.83 (R2), respectively (Additional file 1: Fig. S2). In overload period, the $\mathrm{pH}$ value decreased below 6.4 on day 112 (R1-gradual overload), on day 159 (R1-sudden overload), and on day 160 (R2-gradual overload), respectively, which value we defined as limit for process failure.

High total alkalinity (TA) (about $6000 \mathrm{~g} \mathrm{CaCO}_{3} / \mathrm{L}$ ) was detected in both reactors at the beginning, due to the high alkalinity contained in the inoculum originating from the full-scale biogas plant. During the experiment, TA was maintained at an average of $1814.3 \mathrm{mg} \mathrm{CaCO} / \mathrm{L}$ (R1) and $1871.9 \mathrm{mg} \mathrm{CaCO}_{3} / \mathrm{L}$ (R2) (Fig. 3a1, a2). The result was also in accordance with a previous study, in that TA could remain stable until the $\mathrm{pH}$ fell below 4.3 as a consequence of high VFA concentration [32]. BA suddenly dropped on days 109 and 158 in R1, and day 154 in R2 (Fig. 3c1, c2). Conversely, intermediate alkalinity (IA) suddenly rose on days 105 and 157 in R1, and day 153 in R2 (Fig. 3b1, b2). Although both indicators showed fluctuation under overload conditions, IA proved to be more sensitive, since it got out of balance earlier.

From another perspective, coupled indexes appeared to be more sensitive than single indicators, thus their distinct fluctuations made the identification of acidification response easier. BA/TA decreased sharply on days 105 and 158 in R1, and on day 154 in R2 (Fig. 3d1, d2). Conversely, IA/BA showed a sharp increase on days 105 (from 0.28 to 0.53 ) and 157 (from 0.44 to 0.54 ) in R1, and day 153 (from 0.48 to 0.68 ) in R2 (Fig. 3e1, e2). Unfortunately, all alkalinity indicators showed obvious signs of response delay under sudden overload. It is similar to the report of Li et al. [33] where the warning times of IA/ PA (where PA is the partial alkalinity and is analogous to $\mathrm{BA}$ ) and BA/TA were shortened by 6 days and 2 days, respectively. Ahring et al. [12] also reported that most indicators were suitable for detecting gradual overloads, but were too slow to respond under sudden overload. Significant increase of VFA/BA was found on days 113 and 151 in R1, and day 155 in R2 (Fig. 3f1, f2), and was confirmed by the work of Li et al. [33], who also found VFA/BA increase due to higher OLR in mesophilic AD of vegetable waste.

\section{Simulation results using the BioModel}

The results of the experimental reactor operation simulations are presented in terms of $\mathrm{CH}_{4}$ yield and $\mathrm{CH}_{4} / \mathrm{CO}_{2}$ (Fig. 1), and individual and total VFA 


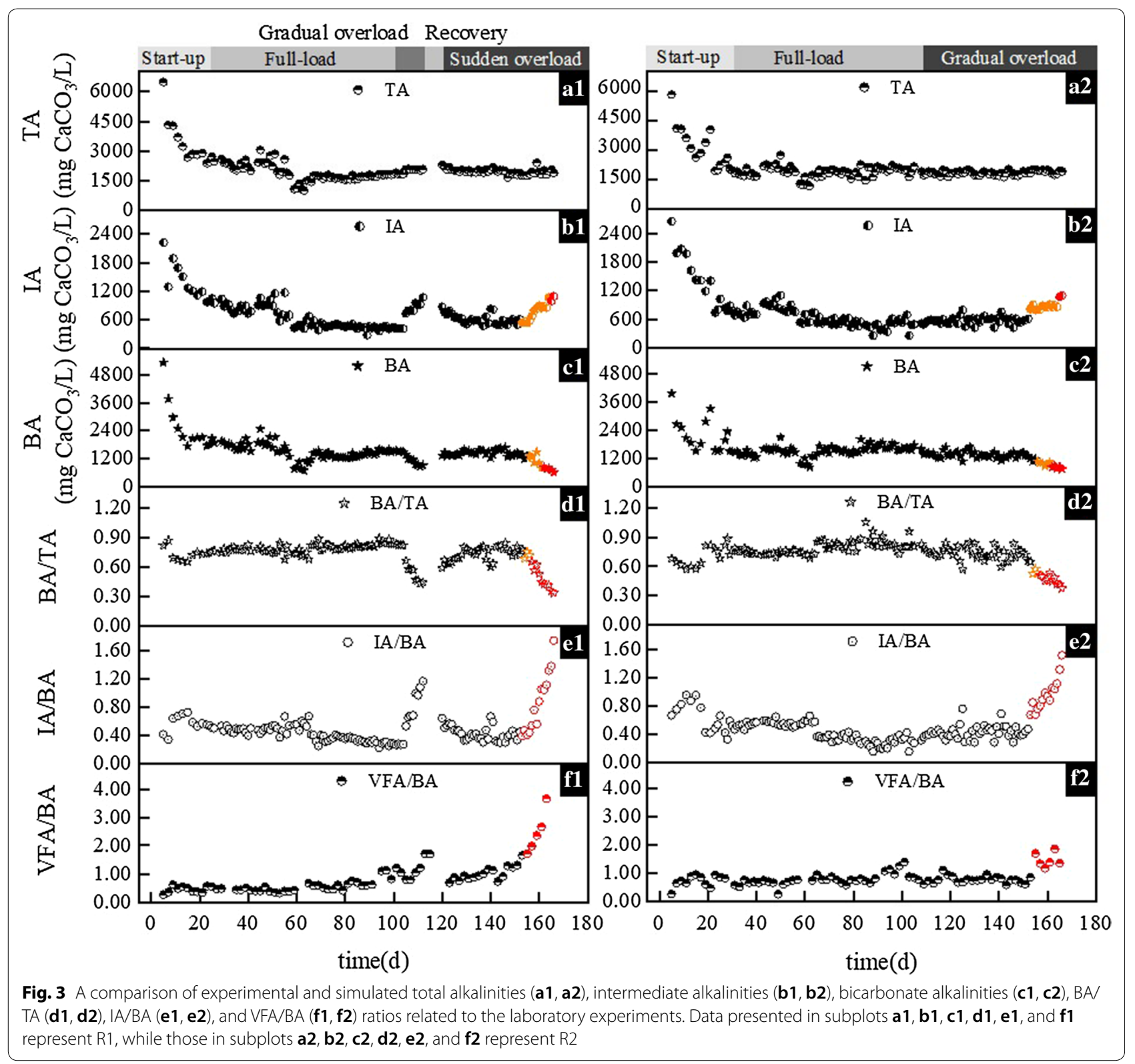

concentrations (Fig. 2). From a qualitative point of view and by looking at the fits between experimental and simulated data curves, it appears that the model was mostly successful in capturing the overall gas and VFA production trends of the two experiments with high accuracy. At the same time, by evaluating the goodness of these fits using statistical measures, relative root mean squared error (rRMSE) and mean absolute percentage error (MAPE) values provide a more detailed overview of simulation accuracy (Table 1). By comparing the visual and statistical measures, biogas and $\mathrm{CH}_{4}$ yield, along with butyric and acetic acid concentration simulations appear to be the most accurate, with the lowest rRMSE and MAPE only slightly above the feasible range (Table 1, values for "Day 0-165"). This deviance is due to a few sections of the dataset, where the simulation-measurement fit was not satisfactory. For example, the gas yield and VFA concentration levels during the reactor startup periods were not matched in the simulations. However, reactor startup periods inherently involve significant stochasticity and, depending on the substrates and reactor history, potential microbial growth lag [34], which are hard to simulate with fixed kinetic models. Deeming this period irrelevant from the perspective of early 
Table 1 rRMSE and MAPE values for goodness-of-fit analyses

\begin{tabular}{|c|c|c|c|c|c|c|c|c|}
\hline \multirow[t]{3}{*}{ Process variable } & \multicolumn{4}{|l|}{ R1 } & \multicolumn{4}{|l|}{$\mathrm{R} 2$} \\
\hline & \multicolumn{2}{|l|}{ rRMSE } & \multicolumn{2}{|l|}{ MAPE (\%) } & \multicolumn{2}{|l|}{ rRMSE } & \multicolumn{2}{|l|}{ MAPE (\%) } \\
\hline & Day 0-165 & Day 30-165 & Day 0-165 & Day 30-165 & Day 0-165 & Day 30-165 & Day 0-165 & Day 30-165 \\
\hline $\mathrm{CH}_{4}$ yield & 0.41 & 0.23 & 57.58 & 19.78 & 0.28 & 0.12 & 39.79 & 11.30 \\
\hline $\mathrm{CH}_{4} / \mathrm{CO}_{2}$ & 2.44 & 2.79 & 31.21 & 31.38 & 1.33 & 1.24 & 25.72 & 25.30 \\
\hline Acetic acid conc. & 0.73 & 0.64 & 52.20 & 43.14 & 0.85 & 0.87 & 54.15 & 52.13 \\
\hline Propionic acid conc. & 1.21 & 1.30 & 79.02 & 78.46 & 0.94 & 0.95 & 64.93 & 61.18 \\
\hline Butyric acid conc. & 0.20 & 0.20 & 61.81 & 60.36 & 0.24 & 0.23 & 70.44 & 68.74 \\
\hline Total VFA conc. & 0.96 & 0.80 & 40.85 & 32.16 & 1.25 & 1.27 & 53.12 & 50.12 \\
\hline
\end{tabular}

warning indication and excluding it from the statistical evaluation, rRMSE and MAPE values of $\mathrm{CH}_{4}$ yield (Table 1, values for "Day 30-165") have improved significantly. On the other hand, VFA simulations showed varying rates of change, with those of $\mathrm{R} 1$ being more positive than R2. A more important difference between the measured and simulated values was, on the other hand, seen in R1, around days 110-120. Here, the drop in $\mathrm{CH}_{4}$ yield and the consecutive process failure were slower in the simulation results compared to the laboratory experience, by approximately 2 days. At the same time, the drop was preceded by a slight increase in the respective yields, potentially owing to an initial positive response of simulated acetoclastic methanogens to an increased OLR. This means that in the model, the immediate response of microbial groups to an increase in substrate availability is a proportional increase in their productivity, which is in most cases followed by their negative response to the gradual accumulation of certain inhibitory compounds. In the case of acetoclastic methanogens, model inhibition was assumed by free ammonia and the saturation of volatile fatty acids, of which the latter was seen both experimentally and during the simulations. However, as the levels of acid saturation were significantly lower in the model simulations than in the physical reactors, inhibition during the simulations appeared to take effect slower than seen experimentally. Nevertheless, the simulations for both R1 and R2 were in general found to be in good agreement with experimental data, therefore they could be used for comparing the experimentally defined early warning indicators with their simulated counterparts. In the short term, this provided an additional method for verifying the quality of indicator selection. In addition, the long-term benefits of such simulations lie in their rapid generality and continuous interpretability: both contributing to the reduction of necessary analytic measurements and process data density. Thus, by means of simulated early warning indicators, monitoring, and forecasting, the fate of the experimental processes could be improved significantly.

\section{Early warning indicators and threshold values The procedure of screening early warning indicators}

Experimental and simulated data were used to screen potentially optimal warning indicators, based on the proposition of three important and mostly qualitative criteria. Firstly, optimal indicators had to show high sensitivity to changes, in the sense that there was enough warning time between an indicator's response point and process failure. Stable acidification response was another vital aspect, as excessive indicator sensitivity to acids may have led to false assumptions. Finally, the low cost of monitoring is essential in practice [20,35], therefore indicators had to be measured economically.

Based on the above selection criteria, reference points for reactor failure are needed for measuring warning time of different parameters. In the current study, these points of failure were declared when at least one of two events happened. The first one concerned the reduction of reactor $\mathrm{pH}$ to less than 6.4, which is well below the optimal $\mathrm{pH}$ range commonly reported for methanogenic archaea [36]. Meanwhile, the other event was the significant reduction of $\mathrm{CH}_{4}$ yield (relative standard deviation (RSD) $>20 \%$ ). $\mathrm{pH}$ and $\mathrm{CH}_{4}$ yield are the most intuitive and easily measured indicators, but relatively insensitive for process destabilization, therefore, their changes were also recommended as the symbol of process failure in previous study [37].

In order to quantify the changes of different indicators at the points of failure, their variation amplitudes were calculated. These amplitudes were expressed on a percentage basis and relative to their steady-state values. Specifically, by comparing the variation amplitude of abrupt changes throughout the different overload modes and types applied in the experimental reactors, maximum and minimum values of each indicator were defined. 


\section{Screening early warning indicators}

According to the experimental data, days 112 and 159 were identified as reference points for measuring the early warning times of different indicators under gradual and sudden overload conditions in R1, and this reference point was day 160 for R2.

The abrupt change dates and values, and warning times of different indicators are shown in Tables 2 and 3. Almost all the parameters have performed certain response to the overload shock. Overall, gas phase indicators provided a delayed response in comparison with liquid phase indicators, only $\mathrm{CH}_{4} / \mathrm{CO}_{2}$ have 6 days warning time under sudden overload. This could probably be due to the properties of corn stalk (CS), given the floating problem caused by low specific gravity can lead to stirring issues and eventually delays in mass transfer from the liquid to the gas phase [38, 39].

It is obvious that parameters' sensitivity is influenced by the overload mode. For the gradual overload, the acidification responses of the various indicators did not show significant difference (3-7 days for individual VFA and 6-7 days for alkalinity) (Tables 2 and

Table 2 The early warning indicators of R1

\begin{tabular}{|c|c|c|c|c|c|c|c|c|c|}
\hline \multirow[t]{2}{*}{ Reactor } & \multirow[t]{2}{*}{ Parameters } & \multirow[t]{2}{*}{ Units } & \multirow{2}{*}{$\begin{array}{l}\text { Date } \\
\text { of abrupt } \\
\text { change (day) }\end{array}$} & \multirow{2}{*}{$\begin{array}{l}\text { Date } \\
\text { of process } \\
\text { failure (day) }\end{array}$} & \multirow{2}{*}{$\begin{array}{l}\text { Warning } \\
\text { time } \\
\text { (day) }\end{array}$} & \multicolumn{2}{|c|}{ Experimental results } & \multicolumn{2}{|c|}{ Simulated results } \\
\hline & & & & & & $\begin{array}{l}\text { Abrupt } \\
\text { change }^{a}\end{array}$ & $\begin{array}{l}\text { Abrupt vs. } \\
\text { steady-state } \\
\text { value }\end{array}$ & $\begin{array}{l}\text { Abrupt } \\
\text { change }\end{array}$ & $\begin{array}{l}\text { Abrupt vs. } \\
\text { steady-state } \\
\text { value }\end{array}$ \\
\hline \multirow[t]{11}{*}{ R1 } & $\mathrm{CH}_{4} / \mathrm{CO}_{2}$ & - & $112(153)$ & $112(159)$ & $0(6)$ & $1.28(1.43)$ & $\begin{array}{c}-23.81 \text { to } \\
-18.48 \% \\
(-16.38 \text { to } \\
-11.73 \%)\end{array}$ & $1.07(1.03)$ & $\begin{array}{l}-2.49 \% \\
(-11.95 \text { to } \\
-1.60 \%)\end{array}$ \\
\hline & Acetate & $g / L$ & $109(147)$ & $112(159)$ & $3(11)$ & $0.39(0.59)$ & $\begin{array}{l}+105.26 \text { to } \\
129.41 \% \\
(+145.83 \%)\end{array}$ & $0.44(0.56)$ & $\begin{array}{l}+27.52 \text { to } \\
94.71 \% \\
(+48.06 \text { to } \\
234.57 \%)\end{array}$ \\
\hline & Propionate & $\mathrm{g} / \mathrm{L}$ & $109(153)$ & $112(159)$ & $3(6)$ & $0.3(0.5)$ & $\begin{array}{c}+130.77 \text { to } \\
172.73 \% \\
(+177.78 \text { to } \\
257.14 \%)\end{array}$ & $0.09(0.12)$ & $\begin{array}{c}+18.46 \text { to } \\
101.87 \% \\
(+101.76 \text { to } \\
274.62 \%)\end{array}$ \\
\hline & VFA & $\mathrm{g} / \mathrm{L}$ & $109(147)$ & $112(159)$ & $3(12)$ & $0.80(0.95)$ & $\begin{array}{l}+50.9 \text { to } \\
105.13 \% \\
\begin{array}{l}(+75.93 \text { to } \\
150 \%)\end{array}\end{array}$ & $0.63(0.76)$ & $\begin{array}{c}+19.49 \text { to } \\
22.20 \% \\
(+56.02 \%)\end{array}$ \\
\hline & IA & $\mathrm{g} \mathrm{CaCO}_{3} / \mathrm{L}$ & $105(157)$ & $112(159)$ & $7(2)$ & $0.79(0.74)$ & $\begin{array}{l}+61.48 \% \\
(+20.68 \text { to } \\
30.65 \%)\end{array}$ & $0.28(0.87)$ & $\begin{array}{c}+18.54 \text { to } \\
19.68 \% \\
(+63.22 \text { to } \\
180.86 \%)\end{array}$ \\
\hline & $B A^{b}$ & $\mathrm{~g} \mathrm{CaCO}_{3} / \mathrm{L}$ & $107(158)$ & $112(159)$ & $5(1)$ & $1.21(1.04)$ & $\begin{array}{c}-20.43 \text { to } \\
-11.10 \% \\
(-23.22 \text { to } \\
-22.85 \%)\end{array}$ & $1.07(0.70)$ & $\begin{array}{l}-32.84 \% \\
(-27.40 \text { to } \\
-50.32 \%)\end{array}$ \\
\hline & VFA/BA & - & $109(147)$ & $112(159)$ & $3(12)$ & $0.77(0.68)$ & $\begin{array}{l}+113.89 \text { to } \\
196.15 \% \\
(+183.33 \%)\end{array}$ & $0.59(0.70)$ & $\begin{array}{l}-23.06 \text { to } \\
-69.02 \% \\
(+199.76 \%)\end{array}$ \\
\hline & BA/TA & - & $105(158)$ & $112(159)$ & $7(1)$ & $0.67(0.56)$ & $\begin{array}{c}-19.28 \text { to } \\
-14.11 \% \\
(-30.86 \text { to } \\
-25.34 \%)\end{array}$ & $0.80(0.43)$ & $\begin{array}{l}-14.38 \% \\
(-51.77 \text { to } \\
-33.80 \%)\end{array}$ \\
\hline & IA/BA & - & $105(157)$ & $112(159)$ & $7(2)$ & $0.53(0.54)$ & $\begin{array}{l}+10.42 \text { to } \\
70.97 \% \\
(+23.26 \%)\end{array}$ & $0.26(1.06)$ & $\begin{array}{l}+20.06 \text { to } \\
26.02 \% \\
(+86.01 \%)\end{array}$ \\
\hline & $\mathrm{pH}$ & - & - & $112(159)$ & - & $6.24(6.38)$ & - & $<6.4$ & - \\
\hline & $\mathrm{CH}_{4}$ yield $^{c}$ & $\mathrm{LCH}_{4} / \mathrm{g} V \mathrm{~S}$ & - & $113(161)$ & - & $0.02(0.12)$ & - & $0.20(0.04)$ & $\begin{array}{l}+47.01 \text { to } \\
68.95 \% \\
(-32.33 \text { to } \\
-13.55 \%)\end{array}$ \\
\hline
\end{tabular}

\footnotetext{
a Values in the units indicated in the "Parameters" column

${ }^{b} \mathrm{BA}$ in simulated results expressed as the absolute change in the sum of dissolved $\mathrm{HCO}_{3}{ }^{-}$and $\mathrm{CO}_{3}{ }^{2-}$ over half a day, in \%

c The values in brackets refer to the corresponding values of sudden overload. - means decrease, and + means increase
} 
Table 3 The early warning indicators of R2

\begin{tabular}{|c|c|c|c|c|c|c|c|c|c|}
\hline \multirow[t]{2}{*}{ Reactor } & \multirow[t]{2}{*}{ Parameters } & \multirow[t]{2}{*}{ Units } & \multirow{2}{*}{$\begin{array}{l}\text { Date } \\
\text { of abrupt } \\
\text { change (day) }\end{array}$} & \multirow{2}{*}{$\begin{array}{l}\text { Date } \\
\text { of process } \\
\text { failure (day) }\end{array}$} & \multirow{2}{*}{$\begin{array}{l}\text { Warning } \\
\text { time } \\
\text { (day) }\end{array}$} & \multicolumn{2}{|c|}{ Experimental results } & \multicolumn{2}{|c|}{ Simulated results } \\
\hline & & & & & & $\begin{array}{l}\text { Abrupt } \\
\text { change }^{a}\end{array}$ & $\begin{array}{l}\text { Abrupt vs. } \\
\text { steady-state } \\
\text { value }\end{array}$ & $\begin{array}{l}\text { Abrupt } \\
\text { change }\end{array}$ & $\begin{array}{l}\text { Abrupt vs. } \\
\text { steady-state } \\
\text { value }\end{array}$ \\
\hline \multirow[t]{11}{*}{ R2 } & $\mathrm{CH}_{4} / \mathrm{CO}_{2}$ & - & 161 & 160 & 0 & 1.00 & $\begin{array}{r}-36.31 \text { to } \\
-25.48 \%\end{array}$ & 0.86 & $\begin{array}{c}-18.01 \text { to } \\
-21.33 \%\end{array}$ \\
\hline & Acetate & $g / L$ & 153 & 160 & 7 & 0.52 & $\begin{array}{c}+57.58 \text { to } \\
73.33 \%\end{array}$ & 0.43 & $\begin{array}{r}+36.43 \text { to } \\
303.98 \%\end{array}$ \\
\hline & Propionate & $g / L$ & 155 & 160 & 5 & 0.98 & $\begin{array}{c}+390.00 \text { to } \\
444.44 \%\end{array}$ & 0.12 & $\begin{array}{r}+27.64 \text { to } \\
206.45 \%\end{array}$ \\
\hline & VFA & $\mathrm{g} / \mathrm{L}$ & 155 & 160 & 5 & 2.15 & $\begin{array}{c}+225.76 \text { to } \\
305.66 \%\end{array}$ & 0.80 & $\begin{array}{r}+76.84 \text { to } \\
193.84 \%\end{array}$ \\
\hline & IA & $\mathrm{g} \mathrm{CaCO}_{3} / \mathrm{L}$ & 153 & 160 & 7 & 0.87 & $\begin{array}{c}+37.09 \text { to } \\
62.18 \%\end{array}$ & 0.32 & $\begin{array}{r}+36.66 \text { to } \\
138.60 \%\end{array}$ \\
\hline & $\mathrm{BA}^{* *}$ & $\mathrm{~g} \mathrm{CaCO}_{3} / \mathrm{L}$ & 154 & 160 & 6 & 1.04 & $\begin{array}{r}-34.29 \text { to } \\
-22.27 \%\end{array}$ & 0.89 & $\begin{array}{l}-60.09 \text { to } \\
-11.46 \%\end{array}$ \\
\hline & VFA/BA & - & 155 & 160 & 5 & 0.64 & $\begin{array}{c}+36.17 \text { to } \\
88.24 \%\end{array}$ & 0.94 & $\begin{array}{c}+106.41 \text { to } \\
338.75\end{array}$ \\
\hline & BA/TA & - & 154 & 160 & 6 & 0.52 & $\begin{array}{l}-36.59 \text { to } \\
-28.77 \%\end{array}$ & 0.71 & $\begin{array}{l}-25.57 \text { to } \\
-13.03 \%\end{array}$ \\
\hline & $\mathrm{A} / \mathrm{BA}$ & - & 153 & 160 & 7 & 0.68 & $\begin{array}{c}+47.83 \text { to } \\
65.95 \%\end{array}$ & 0.34 & $\begin{array}{c}+24.32 \text { to } \\
99.59 \%\end{array}$ \\
\hline & $\mathrm{pH}$ & - & - & 160 & - & 6.33 & - & $<6.4$ & - \\
\hline & $\mathrm{CH}_{4}$ yield ${ }^{* * *}$ & $\mathrm{LCH}_{4} / \mathrm{gVS}$ & - & 163 & - & 0.09 & - & 0.07 & $\begin{array}{c}-69.97 \text { to } \\
52.38 \%\end{array}$ \\
\hline
\end{tabular}

\footnotetext{
a Values in the units indicated in the "Parameters" column

${ }^{b} \mathrm{BA}$ in simulated results expressed as the absolute change in the sum of dissolved $\mathrm{HCO}_{3}{ }^{-}$and $\mathrm{CO}_{3}{ }^{2-}$ over half a day, in \%

c The values in brackets refer to the corresponding values of sudden overload. - means decrease, and + means increase
}

3), regardless of the overload type. Compared with the gradual overload, indicators demonstrated varied acidification responses during sudden overload. More specifically, VFA-related indicators (6-12 days) had longer warning time, while alkalinity and its coupled indicators (1-2 days) had shorter warning time (Tables 2 and $3)$. This contradiction is probably related to the change of alkalinity. At the beginning of the AD process, the effluent taken from the full-scale plant for inoculation provided a high initial alkalinity in both reactors. Later, the gradual overload applied to $\mathrm{R} 1$ generated a large amount of VFA, most of which was consumed by alkalinity that delayed VFA accumulation. By contrast, as the buffer capacity of the $\mathrm{AD}$ system declined before the second (sudden) overload phase, VFA accumulated rapidly and showed a longer warning time.

Besides early warning time, stability and measurability of indicators are also important for monitoring biogas plants [19]. For example, IA and IA/BA, as well as BA and $\mathrm{BA} / \mathrm{TA}$, showed similar warning times in the two reactors (Tables 2 and 3). However, the average RSD values of these indicators during the full-load phase were 9.57 and 11.59 for IA, 8.23 and 10.31 for IA/BA, 6.26 and 6.94 for
$\mathrm{BA}$, and 2.83 and 3.45 for BA/TA, in R1 and R2, respectively. The RSD values of coupled indicators are relatively smaller, which indicates that the coupled indicators are more consistent before overload shock and implies less misjudgment as well. Furthermore, AD is an interrelated process, and the relationship between certain process variables might be the reason for coupled indicators showing better stability than individual ones. Although Li et al. [18] also proposed using coupled indicators to achieve early warning, present study showed that total VFA, acetic, and propionic acids can provide similar warning times in the reactors (Tables 2 and 3). Nevertheless, total VFA can be determined relatively easier than individual VFA in biogas plants [40], making total VFA a more widely acceptable variable for early warning indication. Fortunately, due to the development of detection technology, total VFA and alkalinity can both be monitored online by transducers, titration, or infrared spectroscopy, as well as via online sampling and gas chromatography [41-44].

In addition to the experiment-based identification of indicator variables with the highest early warning potential, results of the simulations were used to calculate the 
same variables numerically and evaluate their warning efficiency in comparison to the empirical values. This approach was unlike any previous work on the topic that the authors reviewed [28, 45-49]. Up until now, early warning indicators were selected mostly based on the offline or online monitoring of different values of VFA, $\mathrm{pH}$, alkalinity, biogas fractions, trace elements, and their various combinations, although, in one instance, stable carbon isotopes of $\mathrm{CH}_{4}$ were also named as potential indicators of process imbalance [50]. These indicator values could then be either evaluated comparatively, or used as inputs to sophisticated control systems. Despite their usually good early warning indicator potential, so far the majority of these solutions remained inapplicable by the industry, mainly due to their limited scope or significant costs involved [51]. Therefore, present simulation-based system could offer a competitive solution for the identification and monitoring of early warning indicators, through its validation by relevant experimental data, application flexibility, customizability at scale, and relatively low price point, when compared to laboratoryintensive processes.

The experimental and simulated variables were compared separately for reactors R1 and R2 and in the gradual (Rg) and sudden overload (Rs) modes, thus creating three distinct indicator groups of interest, referred to as R1 g, R1 s, and R2 g from here onwards. In order to provide a reasonable basis for indicator comparison, reference values for identifying the early warning time in the simulations were chosen according to the experimental points defined earlier. Figure 4 shows a comparison of the experimental and simulated indicators for the three indicator groups described above. For each group and individual indicator, the orange bars enclosed with red (lower) and blue (higher) horizontal lines represent the ranges of percentagewise differences calculated between the reference (critical) indicator values and their highest values measured $(\exp )$ or simulated $(\operatorname{sim})$ during the

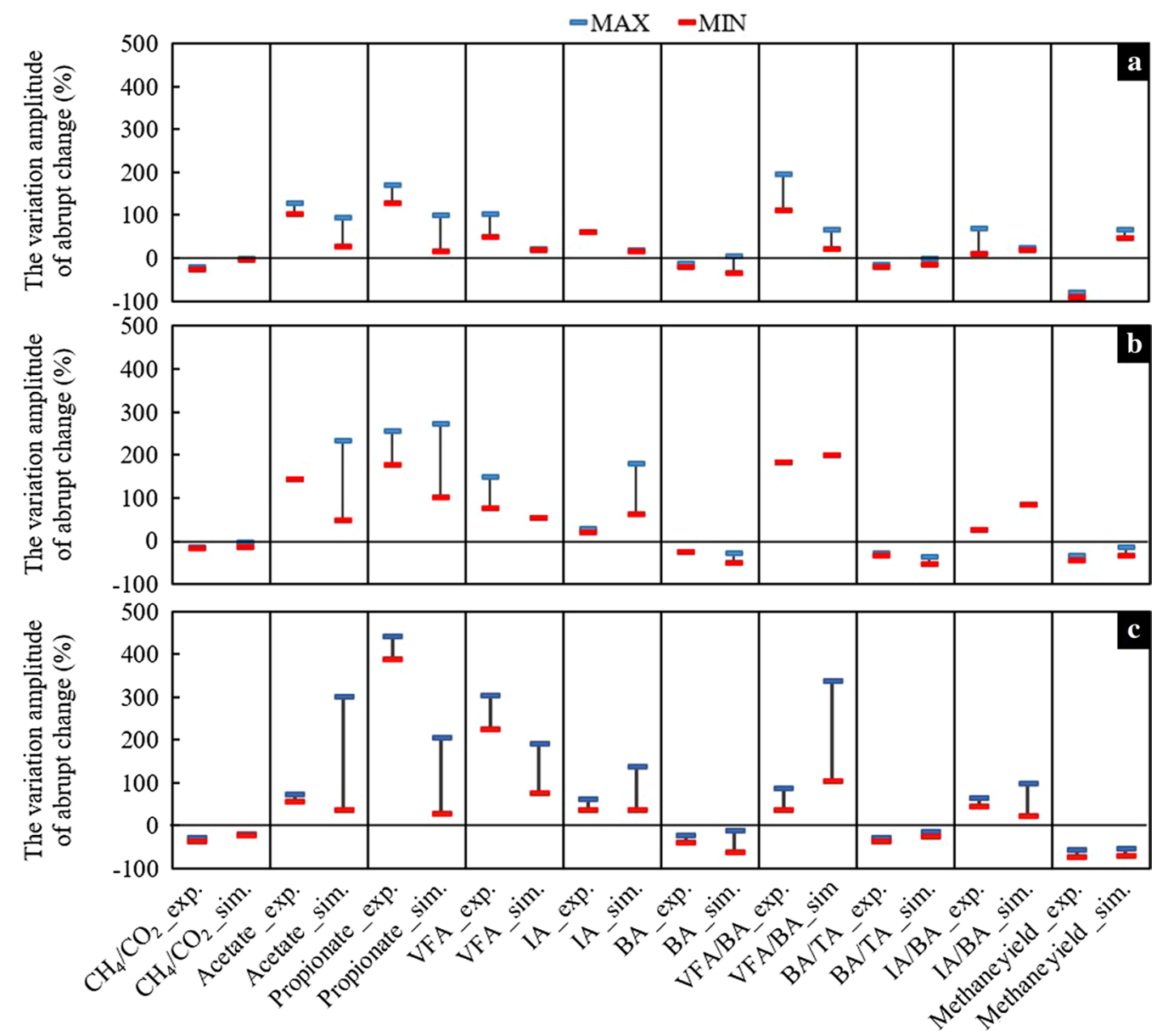

Fig. 4 A comparison of experimental and simulated early warning indicator values in R1 during gradual overload (a) and sudden overload (b), and in R2 during gradual overload (c). Negative values indicate a decrease, while positive values indicate an increase in the value of the respective indicators, at the points of abrupt changes and relative to steady-state values 
different steady-state periods (Tables 2 and 3). As an example, for the indicator group R2 g (Fig. 4c1, c2), the reference value of the experimental propionate indicator (Propionate_exp) was found to be $0.98 \mathrm{~g} / \mathrm{L}$ on day 155 ; then during the five steady-state periods identified from the gradual mode operational data of $\mathrm{R} 2$, the highest experimental values measured were given as $0.20,0.23$, $0.22,0.20$, and $0.19 \mathrm{~g} / \mathrm{L}$, representing, respectively, 390, $326,345,390$, and $416 \%$ changes between their values and the reference value of $0.98 \mathrm{~g} / \mathrm{L}$; finally, selecting the lowest (326\%) and the highest (416\%) changes, the minimum and maximum boundaries of the bar belonging to R2 g Propionate_exp (Fig. 4c1, c2) were given. The ranges for the simulated propionate indicator (Propionate_sim), along with all the other indicators were calculated in an identical manner. In cases where the minimum and maximum indicator values were equal, average indicator values were used for the calculation (see standalone red horizontal lines).

Figure 4 shows that the experimental and simulated difference ranges agreed well for some indicators, while for others they were significantly different. Given that most of the indicators were partially or completely dependent on VFA concentrations or alkalinity (VFA and alkalinity being interrelated), changes in these two types of process variables could influence the results to a great extent. Regarding the generation of experimental and simulated VFA data points, a major influencing factor was how accurately the model considered the conversion of initial compounds to intermediate and terminal products, compared to reality. This implies that under experimental conditions, the conversion of complex organic substrates to VFA and then further to gases is a function of a series of stochastic and microbial community-driven events, while model simulations, which are relatively simplified descriptions of reality, are generated assuming structured kinetic equations and stoichiometric yield coefficients. Such fundamental differences could inherently lead to deviations between measured and simulated VFA concentrations, despite the good agreement of the experimental and simulated $\mathrm{CH}_{4}$ yields (Fig. 1a1, a2) showing that the overall model mass balances are otherwise reliable. On the other hand, the simulation of the various alkalinity fractions posed considerable difficulties. Under laboratory conditions, the alkalinity of a sample is commonly measured through titrimetry, and it is the preferable method for the routine analysis of anaerobic digestion samples as well, due to its speed, simplicity and competitive price [52]. Nonetheless, it involves a significant level of uncertainty when used for the offline measurement of dissolved carbonate concentration in AD samples with inhomogeneous matrices [53]. Meanwhile, as the model cannot simulate titration, simplification was necessary.
It was decided that using the simulation results, the BA of the reactor would be calculated by using the bicarbonate and carbonate ion fractions calculated by the model, while IA would be represented by the sum of acetic, propionic and butyric acids, expressed in terms of acetic acid equivalents. However, this simplification meant that any inaccuracies in the simulation of these compounds, together with the uncertainties brought about by the titration method would potentially cause disagreements between experimental and simulated alkalinity results. For this reason, this factor was considered during the evaluation of the comparative results.

Considering the overall sensitivity, stability and measurability of indicators and based on the experimental and simulation results, IA/BA and VFA were selected as optimal early warning indicators. Further to that, IA, BA and VFA/BA were defined as auxiliary indicators for the diagnosis of the AD system treating CS. IA/BA was also suggested as warning indicator in other lab-scale research [32], and an industrial scale research [38], due to its sensitivity to pronounced changes under overloading conditions. VFA was usually recommended as warning indicator $[12,18]$.

\section{Threshold value}

The abrupt change values and their change amplitude in the previously selected main (IA/BA and VFA) and auxiliary (IA, BA and VFA/BA) early warning indicators were investigated in current study. The variation amplitudes of abrupt changes in indicators monitored during experiments and simulation are shown in Fig. 4, and the accurate values were shown in Tables 2 and 3. The abrupt change value of IA/BA was below 0.7 , which was 0.53 for organic gradual overload (R1 g), 0.54 for organic sudden overload (R1 s) and 0.68 for hydraulic gradual overload (R2 g), respectively. Meanwhile, Martín-González et al. [32] proposed the critical value of IA/PA to be 0.24 for municipal waste $\left(37^{\circ} \mathrm{C}\right)$, and in another study Ferrer et al. [38] found this number to be 0.72 for sewage sludge $\left(55^{\circ} \mathrm{C}\right)$. This divergence, however, may be the result of differences in feedstock composition and $\mathrm{AD}$ operating conditions. Consequently, compared with providing a determined threshold, observing the relative variation for indicators might be a more promising strategy, while evaluating the effectiveness of early warning indicators. This conclusion found further support in previous studies $[12,18]$.

Accordingly, an acidification risk that requires attention would appear in present AD processes when the IA/ BA changed more than $10 \%$ in the experiment or $20 \%$ in the simulation, based on the steady-state data.

The abrupt change values of VFA were $0.80 \mathrm{~g} / \mathrm{L}(\mathrm{R} 1 \mathrm{~g})$, $0.95 \mathrm{~g} / \mathrm{L}(\mathrm{R} 1 \mathrm{~s})$ and $2.15 \mathrm{~g} / \mathrm{L}$ (R2 g), respectively. Compared to the average values during the steady-state 
period, if the VFA increased more than 51\% (experimental data) or $19 \%$ (simulation data), the biogas system would potentially be at risk from instability.

The abrupt change values of IA, BA and VFA/BA in this study were lower than 0.90 , higher than 1.05 and lower than 0.80 , respectively. When the IA value increased by nearly $20 \%$, BA value decreased about $11 \%$ and VFA/BA value increased approximately $30 \%$. This implied that the biogas system was imbalanced, thus attention should be paid and necessary actions might have to be taken to regulate the AD process.

While based on the assessment of several relevant publications, above discussion could potentially be extended by future analyses of the available literature on the early warning indicators in AD. These, together with experiments carried out and evaluated in a manner similar to the one hereby presented, could offer further model verification, deeper insights into the dynamic behavior of such interconnected processes and eventually provide optimized early warning indicators for biogas plants.

\section{Conclusion}

Monitoring and providing early warning are essential operations in the AD process. Using a mathematical model to simulate the selected experimental process variables provided good data fit and played a key role in the evaluation of the early warning indicators. Based on both experimental and simulated results, the optimal early warning indicators were identified to be IA/BA and VFA. Besides, IA, BA, and VFA/BA could be used as auxiliary indicators for diagnosing the AD system of CS. It is concluded that this modeling can be a promising tool for monitoring the change signals from early warning indicators and improving the standards of $\mathrm{AD}$ plant operation.

\section{Methods}

\section{Feedstock and inoculum}

Corn stalk was obtained from Weichang County, Hebei, China. The collected corn stalk was dried and smashed to approximately $3 \mathrm{~mm}$. The inoculum, obtained from an anaerobic reactor in a wastewater treatment plant (Beijing, China), was acclimated at mesophilic temperature by feeding with pig manure for 2 weeks. The properties of corn stalk and inoculum were shown in Table 4.

\section{Experimental setup}

The experiment was carried out using two identical $20 \mathrm{~L}$ continuously stirred tank reactors (CSTR) having $17 \mathrm{~L}$ working volume. The reactors were maintained at mesophilic conditions $\left(35 \pm 1{ }^{\circ} \mathrm{C}\right.$ ) by a heating water bath (SY200, Changfeng Instrument and Apparatus Company, Beijing, China) and were continuously mixed at a stirring speed of $60 \mathrm{rpm}$.
Table 4 The properties of the corn stalk and seeding sludge

\begin{tabular}{|c|c|c|c|}
\hline Parameters & Unit & Corn stalk & Inoculum \\
\hline TS & $\%$ & $90.14 \pm 0.32$ & $4.10 \pm 0.05$ \\
\hline VS & $\%$ TS & $84.81 \pm 0.11$ & $2.20 \pm 0.02$ \\
\hline Crude fiber & $\%$ TS & $37.25 \pm 0.19$ & - \\
\hline Crude protein & $\%$ TS & $0.49 \pm 0.03$ & - \\
\hline $\mathrm{C}$ & $\%$ TS & $39.64 \pm 0.08$ & - \\
\hline $\mathrm{N}$ & $\%$ TS & $0.70 \pm 0.02$ & - \\
\hline $\mathrm{H}$ & $\%$ TS & $6.38 \pm 0.04$ & - \\
\hline S & $\%$ TS & $0.16 \pm 0.01$ & - \\
\hline $\mathrm{C} / \mathrm{N}$ & $-^{a}$ & $56.62 \pm 0.45$ & - \\
\hline $\mathrm{pH}$ & - & - & $7.96 \pm 0.03$ \\
\hline
\end{tabular}

Reactor 1 (R1) operated at stepwise elevated OLR by increasing influent feedstock concentration. The experiment in R1 was divided into two phases, which were denoted as gradual overload (day 0-113 with OLR from 1.50 to $2.99 \mathrm{~g} \mathrm{VS} /(\mathrm{L}$ day)) and sudden overload (day 121-165 with OLR from 1.50 to $3.37 \mathrm{~g}$ VS/(L day)). Due to process inhibition, the $\mathrm{AD}$ system started recovering from day 114 to 120 , during which period a re-inoculation was made, substrate feeding was stopped, and the reactor effluent was recycled as feed. R1 was operated at a fixed HRT of 25 days during the whole experiment. At the same time, Reactor 2 (R2) was operated at a gradually increasing OLR, by shortening HRT and keeping influent feedstock concentration at $6 \%$ TS. Both reactors were kept operating until the process completely failed. The operational parameters and periods of the experiment are presented in Table 5 .

Produced biogas was collected in a gas bag, and the gas volume was measured by a gas flowmeter (LML-1, Changchun auto filter co., Ltd, Jilin, China). The effluent was drawn daily for the analysis of pH, VFA, TA, BA, IA, TS and VS.

\section{Analytical methods}

Total solid (TS) and volatile solid (VS) were measured according to the standard methods [54]. Crude protein was estimated by multiplying the total Kjeldahl nitrogen by 6.25 and the total Kjeldahl nitrogen was measured by a Kjeldahl apparatus (K1305A, Sonnen Automated Analysis Instrument Co., Ltd., Shanghai, China). Crude fiber was determined using a fiber analyzer (Model A220, ANKOM Technology Corporation, NY, USA). Organic elemental components of the corn stalk were determined using an elemental analyzer (Exeter Analytical, Inc. CE-440 Elemental Analyzer, Chicago, USA). 
Table 5 The operational parameters and duration of the experiment

\begin{tabular}{|c|c|c|c|c|c|}
\hline Reactor no. & Feeding phase & $\begin{array}{l}\text { Feed concentration } \\
\text { (TS\%) }\end{array}$ & HRT (d) & Duration & $\begin{array}{l}\text { OLR } \\
\text { (g VS/(L day)) }\end{array}$ \\
\hline \multirow[t]{9}{*}{ R1 } & Replacement & 4 & 25 & 0-25 day & 1.50 \\
\hline & Full-load & 4 & 25 & 26-50 day & 1.50 \\
\hline & & 6 & 25 & 51-100 day & 2.24 \\
\hline & Gradual overload & 8 & 25 & $101-113$ day & 2.99 \\
\hline & Recovery & 0 & 25 & 114-120 day & 0.00 \\
\hline & Sudden overload & 4 & 25 & $121-128$ day & 1.50 \\
\hline & & 6 & 25 & 129-137 day & 2.24 \\
\hline & & 8 & 25 & 138-146 day & 2.99 \\
\hline & & 9 & 25 & 147-165 day & 3.37 \\
\hline \multirow[t]{5}{*}{ R2 } & Replacement & 6 & 30 & 0-30 day & 1.87 \\
\hline & Full-load & 6 & 30 & 31-60 day & 1.87 \\
\hline & & 6 & 25 & $61-110$ day & 2.24 \\
\hline & Gradual overload & 6 & 20 & 111-150 day & 2.81 \\
\hline & & 6 & 15 & $151-170$ day & 3.74 \\
\hline
\end{tabular}

Biogas composition $\left(\mathrm{CH}_{4}, \mathrm{H}_{2}\right.$ and carbon dioxide) was determined by a gas chromatograph (1490, Agilent Technologies, USA) equipped with a thermal conductivity detector as previously described [55]. Liquid samples were centrifuged at $4000 \mathrm{rpm}$ for $10 \mathrm{~min}$ and then used for the chemical analyses. Before VFA analysis, samples were filtered through a $0.22 \mu \mathrm{m}$ membrane. The VFA concentrations were measured by a high performance liquid chromatograph (LC-10A, Shimadzu Corporation, Kyoto, Japan), according to the method proposed by [55]. Alkalinity and $\mathrm{pH}$ were tested by an automatic potentiometric titrator (ZDJ-4B, Shanghai INESA Scientific Instrument Co., Ltd, China), with a glass and calomel electrode used as the indicator and reference electrode, respectively. For titration, $0.20 \mathrm{~mol} / \mathrm{L} \mathrm{HCl}$ was used as titrant, and the system was calibrated with anhydrous $\mathrm{Na}_{2} \mathrm{CO}_{3}$. IA, PA, and TA were determined using a three-point method [56], by recording the $\mathrm{HCl}$ consumption at the respective $\mathrm{pH}$ points of $5.75,4.3$, and 3.8 , and converting those values to calcium carbonate $\left(\mathrm{CaCO}_{3}\right)$ equivalents (see Eq. (1)).

$$
\begin{aligned}
& \text { Alkalinity }\left(\mathrm{mg} \mathrm{CaCO}_{3} / \mathrm{L}\right) \\
& =\frac{\mathrm{HCl} \text { concentration } \times \mathrm{HCl} \text { consumption volume } \times 50.05}{\text { Sample volume }} \\
& \quad \times 1000,
\end{aligned}
$$

where 50.05 is a coefficient used to convert alkalinity units from $\mathrm{mEq} / \mathrm{L}$ to $\mathrm{mg} \mathrm{CaCO}_{3} / \mathrm{L}$. BA is estimated by multiplying the PA by 1.25 according to Anderson and Yang [56]. To simplify the data analysis, only BA was analyzed in current study.

\section{Statistical method}

The state of the reactor was defined as steady state when the daily biogas production was within $10 \%$ variation, for at least 6 consecutive days [57]. The date of process failure was determined by the time point where a significant decrease (RSD > 20\%) appeared in the $\mathrm{CH}_{4}$ yield.

Relative standard deviations (RSDs) were calculated according to Eq. 2, for a quantitative assessment of fluctuations in daily indicator values compared with the previous day.

$$
\operatorname{RSD}=\frac{S}{\bar{x}} \times 100 \%=\frac{\sqrt{\sum_{i=1}^{2}\left(x_{i}-\bar{x}\right)^{2}}}{\bar{x}} \times 100 \%
$$

In the above equation, $S$ is the standard deviation of the measured indicator value compared to the previous day, and $\bar{x}$ is the average of the values at day $\mathrm{i}$ and $\mathrm{i}-1$. The larger the RSD value, the greater the fluctuation. In the current study, RSD $>10 \%$ (yellow symbol in all figures) and RSD $>20 \%$ (red symbol in all figures) were identified as the signs of slightly and highly unstable process, respectively. Thereby, the date when RSD exceeds $20 \%$ was determined as the time point where sudden changes took place.

For the quantification of goodness of fit between simulations and experimental data, relative root meansquared error (rRMSE) and mean absolute percentage error (MAPE) were used, according to Eqs. 3 and 4.

$$
\mathrm{rRMSE}=\frac{1}{\bar{y}_{\exp }} \sqrt{\frac{1}{n} \sum_{i=1}^{n}\left(y_{\exp _{i}}-y_{\text {sim }_{i}}\right)^{2}}
$$




$$
\text { MAPE }=\frac{100}{n} \sum_{i=1}^{n}\left|\frac{y_{\exp _{i}}-y_{\text {sim }_{i}}}{y_{\exp _{i}}}\right|,
$$

where $y_{\text {sim }_{i}}$ and $y_{\text {exp }}$, respectively, represent a single simulated or measured (experimental) data value, while $\overline{y_{\exp }}$ is the average of all experimental data values and $n$ is the total number of experimental data points available. RMSE is commonly used for $\mathrm{AD}$ model evaluation $[58,59]$ and in certain cases, offers advantages over other measures, especially when sensitivity to large errors between experimental and simulated data points is required [60]. After dividing RMSE by the mean of the experimental data points involved, the resulting rRMSE can be compared through different variable datasets, without having to consider its specific units. While rRMSE is defined in the range of 0 (no error) to infinity (no fit) and can therefore take significantly different values for different variables, MAPE is expressed in percentages. By design, it takes values between 0 and $100 \%$ for simulated data points that are at most double as large as experimental ones, but is in general said to produce reliable simulations when MAPE is less than 50\% [61]. Consequently, it offers a complementary metric for error assessment less distorted by extreme data points, and provides a holistic view of dynamic simulation regression [62].

\section{Mathematical model simulations}

For the simulation of the two experimental reactors and the different overload conditions, an advanced bioconversion model (BioModel) was used. The model was developed by Angelidaki et al. [63, 64], and was later extended by Kovalovszki et al. [65] and Lovato et al. [66], considering various anaerobic co-digestion scenarios for validation. Compared to the extended model established earlier, however, two minor changes were made in the present model implementation. Of the two, the first involved the removal of ammonia as a microbial growth limiting substrate from the model's kinetic equations, while through the second, the acetic acid inhibition effect on acetolactic methanogens was replaced by a total VFA inhibition effect. Former change was considered reasonable, given that the single substrate in these experiments-corn stalk-is a negligible source of ammonia. Meanwhile, the argument for extending the range of VFA inhibition on methanogens lies in their sensitivity to undissociated organic acids [67], as well as the dilute reactor medium, which in general might limit the availability of physical shelter and granule-forming sites for methanogens [68, 69]. The above described VFA inhibition effect was kinetically controlled similar to the original acetic acid inhibition effect, using inhibition constants with manually estimated values of $315 \mathrm{mg} / \mathrm{L}$ and
$365 \mathrm{mg} / \mathrm{L}$ for R1 and R2, respectively. By comparison, similar inhibition constants found in published literature take values on a wide range, from $10 \mathrm{~s}$ to $1000 \mathrm{~s} \mathrm{mg/L}$ and considering either acetic and propionic acid as the main inhibitors, or all VFA collectively [64, 70-73]. The values reported depend largely on the specific reactor conditions and substrates, therefore the low values used in this work can be justified by the highly dilute reactor contents and the lack of solid buffers (potentially leading to faster acidification) and the general sensitivity of methanogenic archaea to the accumulation of acids. In addition, the slight difference in the magnitude of the values estimated appears negligible compared to the above literature sources, and can be attributed to reactor-specific conditions.

\section{Additional files}

Additional file 1: Fig. S1. Variation of effluent TS and VS in (a) R1 and (b) R2. Fig. S2. Variation of pH in (a) R1 and (b) R2.

\section{Abbreviations}

AD: anaerobic digestion; BA: bicarbonate alkalinity; BioModel: bioconversion model; CS: corn stalk; CSTR: continuously stirred tank reactors; HRT: hydraulic retention time; IA: intermediate alkalinity; OLR: organic loading rates; R: reactor; RSD: relative standard deviations; TA: total alkalinity; TS: total solid; VFA: volatile fatty acid; VS: volatile solid.

\section{Authors' contributions}

ND and YW designed the entire research project; YW and JP executed the experimental work; AK executed the computational work; YW and AK prepared the manuscript; ND, CL, HL. and IA reviewed the manuscript; and ND, YW, IA, and AK revised the manuscript. All authors read and approved the final manuscript.

\section{Author details \\ ${ }^{1}$ College of Water Resources and Civil Engineering, China Agricultural Uni- versity, Beijing 100083, China. ${ }^{2}$ Department of Environmental Engineering, Technical University of Denmark, 2800 Kgs. Lyngby, Denmark. ${ }^{3}$ Key Laboratory of Nonpoint Source Pollution Control, Ministry of Agriculture/Institute of Agri- cultural Resources and Regional Planning, Chinese Academy of Agricultural Sciences, Beijing 100081, China.}

\section{Acknowledgements}

Not applicable.

Competing interests

The authors declare that they have no competing interests.

Availability of data and materials

All datasets supporting the conclusions of this study are included in this submitted article and its Additional files.

\section{Consent for publication \\ Not applicable.}

Ethics approval and consent to participate

Not applicable. 


\section{Funding}

This work was supported by the National Natural Science Foundation of China (51506217), the National Key Research and Development Program (2018YFD0800803), and by the open fund of Key Laboratory of Nonpoint Source Pollution Control, Ministry of Agriculture, P.R.China.

\section{Publisher's Note}

Springer Nature remains neutral with regard to jurisdictional claims in published maps and institutional affiliations.

Received: 29 January 2019 Accepted: 16 April 2019

Published online: 03 May 2019

\section{References}

1. Sawatdeenarunat C, Surendra KC, Takara D, Oechsner H, Khanal SK. Anaerobic digestion of lignocellulosic biomass: challenges and opportunities. Bioresour Technol. 2015;178:178-86.

2. Yang L, Xu F, Ge X, Li Y. Challenges and strategies for solid-state anaerobic digestion of lignocellulosic biomass. Renew Sustain Energy Rev. 2015:44:824-34.

3. Shi ZL, Jia T, Wang YJ, Wang JC, Sun RH, Wang F, Li X, Bi YY. Comprehensive utilization status of crop straw and estimation of carbon from burning in China. J Agric Resour Reg Plann. 2017;38:32-7.

4. Hong J, Ren L, Hong J, Xu C. Environmental impact assessment of corn straw utilization in China. J Cleaner Prod. 2016;112:1700-8.

5. Weiland P. Biogas production: current state and perspectives. Appl Microbiol Biotechnol. 2010;85:849-60.

6. Paul S, Dutta A. Challenges and opportunities of lignocellulosic biomass for anaerobic digestion. Resour Conserv Recycl. 2018;130:164-74.

7. Bhatnagar A, Sain M. Processing of cellulose nanofiber-reinforced composites. J Reinf Plast Compos. 2016;24(12):1259-68.

8. Sun L, Liu T, Müller B, Schnürer A. The microbial community structure in industrial biogas plants influences the degradation rate of straw and cellulose in batch tests. Biotechnol Biofuels. 2016;9(1):128.

9. Zhou J, Yang J, Yu Q, Yong X, Xie X, Zhang L, Wei P, Jia H. Different organic loading rates on the biogas production during the anaerobic digestion of rice straw: a pilot study. Bioresour Technol. 2017;244:865-71.

10. Li D, Liu S, Mi L, Li Z, Yuan Y, Yan Z, Liu X. Effects of feedstock ratio and organic loading rate on the anaerobic mesophilic co-digestion of rice straw and cow manure. Bioresour Technol. 2015;189:319-26.

11. Ward AJ, Hobbs PJ, Holliman PJ, Jones DL. Optimization of the anaerobic digestion of agricultural resources. Bioresour Technol. 2008;99:7928-40.

12. Ahring $B$, Sandberg $M$, Angelidaki I. Volatile fatty acids as indicators of process imbalance in anaerobic digestors. Appl Microbiol Biotechnol. 1995;43(3):559-65.

13. Hecht C, Griehl C. Investigation of the accumulation of aromatic compounds during biogas production from kitchen waste. Bioresour Technol. 2009;100:654-8.

14. Cook S, Skerlos S, Raskin L, Love N. A stability assessment tool for anaerobic co-digestion. Water Res. 2007;112:19-28

15. Ugwuanyi J, Harvey L, Mcneil B. Protease and xylanase activities and thermophilic populations as potential process monitoring tools during thermophilic aerobic digestion. J Chem Technol Biotechnol. 2004;79:30-8.

16. Munk B, Lebuhn M. Process diagnosis using methanogenic Archaea in maize-fed, trace element depleted fermenters. Anaerobe. 2014:29:22-8.

17. Poirier S, Bize A, Bureau C, Bouchez T, Chapleur O. Community shifts within anaerobic digestion microbiota facing phenol inhibition: towards early warning microbial indicators? Water Res. 2016;100:296-305.

18. Li L, He QM, Wei YM, He Q, Peng XY. Early warning indicators for monitoring the process failure of anaerobicigestion system of food waste. Bioresour Technol. 2014;171:491-4.

19. Castellano M, Ruiz-Filippi G, Gonzalez W, Roca E, Lema J. Selection of variables using factorial discriminant analysis for the state identification of an anaerobic UASB-UAF hybrid pilot plant, fed with winery effluents. Water Sci Technol. 2007;56:139-45.

20. Kleyböcker A, Liebrich M, Verstraete W, Kraume M, Würdemann H. Early warning indicators for process failure due to organic overloading by rapeseed oil in one-stage continuously stirred tank reactor, sewage sludge and waste digesters. Bioresour Technol. 2012;123:534-41.

21. Pullammanappallil PC, Chynoweth DP, Lyberatos G, Svoronos SA. Stable performance of anaerobic digestion in the presence of a high concentration of propionic acid. Bioresour Technol. 2001;78:165-9.

22. Holm-Nielsen J, Al Seadi T, Oleskowicz-Popiel P. The future of anaerobic digestion and biogas utilization. Bioresour Technol. 2009;100:5478-84.

23. Lyberatos G, Skiadas IV. Modelling of anaerobic digestion-a review. Global Nest Int J. 1999;1:63-76.

24. Goux X, Calusinska M, Lemaigre S, Marynowska M, Klocke M, Delfosse $P$, et al. Microbial community dynamics in replicate anaerobic digesters exposed sequentially to increasing organic loading rate, acidosis, and process recovery. Biotechnol Biofuels. 2015;8:122.

25. Donoso-Bravo A, Mailier J, Martin C, Rodríguez J, Aceves-Lara CA, Wouwer AV. Model selection, identification and validation in anaerobic digestion: a review. Water Res. 2011;45(17):5347-64.

26. Zealand AM, Roskilly AP, Graham DW. The effect of feeding frequency and organic loading rate on the anaerobic digestion of Chinese rice straw. Energy Procedia. 2017;105:62-7.

27. Molina F, Castellano M, García C, Roca E, Lema JM. Selection of variables for on-line monitoring, diagnosis, and control of anaerobic digestion processes. Water Sci Technol. 2009;60:615-22.

28. Boe K, Batstone DJ, Steyer JP, Angelidaki I. State indicators for monitoring the anaerobic digestion process. Water Res. 2010:44(20):5973-80.

29. Xiao KK, Guo CH, Zhou Y, Maspolim Y, Ng WJ. Acetic acid effects on methanogens in the second stage of a two-stage anaerobic system. Chemosphere. 2016;144:1498-504.

30. Azim AA, Rittmann KMR, Fino D, Bochmann G. The physiological effect of heavy metals and volatile fatty acids on Methanococcus maripaludis S2. Biotechnol Biofuels. 2018;11(1):301.

31. Ahring $B$, Ibrahim A, Mladenovska Z. Effect of temperature increase from 55 to $65^{\circ} \mathrm{C}$ on performance and microbial population dynamics of an anaerobic reactor treating cattle manure. Water Res. 2001;35(10):2446-52.

32. Martín-González L, Font X, Vicent T. Alkalinity ratios to identify process imbalances in anaerobic digesters treating source-sorted organic fraction of municipal wastes. Biochem Eng J. 2013;76:1-5.

33. Li D, Ran Y, Chen L, Cao Q, Li Z, Liu X. Instability diagnosis and syntrophic acetate oxidation during thermophilic digestion of vegetable waste. Water Res. 2018;139:263-71.

34. Vadasz P, Vadasz AS. Predictive modeling of microorganisms: LAG and LIP in monotonic growth. Int J Food Microbiol. 2005;102(3):257-75.

35. Switzenbaum MS, Giraldo-Gomez E, Hickey RF. Monitoring of the anaerobic methane fermentation process. Enzyme Microb Technol. 1990;12:722-30.

36. Liu Y, Whitman WB. Metabolic, phylogenetic, and ecological diversity of the methanogenic archaea. Ann N Y Acad Sci. 2008;1125(1):171-89.

37. Chen Y, Cheng JJ, Creamer K. Inhibition of anaerobic digestion process: a review. Bioresour Technol. 2008;99:4044-64.

38. Ferrer I, Vazquez F, Font X. Long term operation of a thermophilic anaerobic reactor: process stability and efficiency at decreasing sludge retention time. Bioresour Technol. 2010;101:2972-80.

39. Sukhesh M, Rao P. Anaerobic digestion of crop residues: technological developments and environmental impact in the Indian context. Biocatal Agric Biotechnol. 2018;16:513-28.

40. Madsen $\mathrm{M}$, Holm-Nielsen JB, Esbensen $\mathrm{KH}$. Monitoring of anaerobic digestion processes: a review perspective. Renew Sustain Energy Rev. 2011;15:3141-55.

41. Rudnitskaya A, Legin A. Sensor systems, electronic tongues and electronic noses, for the monitoring of biotechnological processes. J Ind Microbiol Biotechnol. 2008;35:443-51.

42. Steyer JP, Bouvier JC, Conte T, Gras P, Harmand J, Delgenes JP. On-line measurements of COD, TOC, VFA, total and partial alkalinity in anaerobic digestion processes using infra-red spectrometry. Water Sci Technol. 2002;45:133-8.

43. Sun H, Guo J, Wu S, Liu F, Dong R. Development and validation of a simplified titration method for monitoring volatile fatty acids in anaerobic digestion. Waste Manage. 2017;67:43-50.

44. Boe K, John D, Batstone DJ, Angelidaki I. An innovative online VFA monitoring system for the anerobic process, based on headspace gas chromatography. Biotechnol Bioeng. 2010;96(4):712-21. 
45. Dong F, Zhao QB, Li WW, Sheng GP, Zhao JB, Tang Y, Yu HQ, Kubota K, Li YY, Harada H. Novel online monitoring and alert system for anaerobic digestion reactors. Environ Sci Technol. 2011;45(20):9093-100.

46. Moeller $L$, Zehnsdorf A. Process upsets in a full-scale anaerobic digestion bioreactor: over-acidification and foam formation during biogas production. Energy Sustain Soc. 2016;6(1):30.

47. He Q, Li L, Peng X. Early warning indicators and microbial mechanisms for process failure due to organic overloading in food waste digesters. J Environl Eng. 2017;143(12):04017077.

48. Li D, Chen L, Liu X, Mei Z, Ren H, Cao Q, Yan Z. Instability mechanisms and early warning indicators for mesophilic anaerobic digestion of vegetable waste. Bioresour Technol. 2017;245:90-7.

49. Röhlen DL, Pilas J, Dahmen M, Keusgen M, Selmer T, Schöning MJ. Toward a hybrid biosensor system for analysis of organic and volatile fatty acids in fermentation processes. Front Chem. 2018;6:284

50. Polag D, May T, Müller L, König H, Jacobi F, Laukenmann S, Keppler F. Online monitoring of stable carbon isotopes of methane in anaerobic digestion as a new tool for early warning of process instability. Bioresour Technol. 2015;197:161-70.

51. Wu D, Li L, Zhao X, Peng Y, Yang P, Peng X. Anaerobic digestion: a review on process monitoring. Renew Sustain Energy Rev. 2019;103:1-2.

52. Lahav O, Morgan BE. Titration methodologies for monitoring of anaerobic digestion in developing countries - a review. J Appl Chem Biotechnol. 2004;79(12):11.

53. Sun H, Wu S, Dong R. Monitoring volatile fatty acids and carbonate alkalinity in anaerobic digestion: titration methodologies. Chem Eng Technol. 2016;39(4):599-610.

54. APHA. Standard methods for the examination of water and wastewater. Washington, DC: American Public Health Association; 2005.

55. Li RR, Duan N, Zhang DM, Li BM, Zhang YH, Liu ZD, Dong TL. Anaerobic co-digestion of chicken manure and microalgae Chlorella sp.: methane potential, microbial diversity and synergistic impact evaluation. Waste Manage. 2017:68:120-7.

56. Anderson GK, Yang G. Determination of bicarbonate and total volatile acid concentration in anaerobic digesters using a simple titration. Water Environ Res. 1992;64(1):53-9.

57. De Francisci D, Kougias P, Treu L, Campanaro S, Angelidaki I. Microbial diversity and dynamicity of biogas reactors due to radical changes of feedstock composition. Bioresour Technol. 2015;176:56-64.

58. Velázquez-Martí B, Meneses-Quelal OW, Gaibor-Chavez J, Niño-Ruiz Z Review of mathematical models for the anaerobic digestion process. In: Biogas. IntechOpen; 2018. https://doi.org/10.5772/intechopen.80815.

59. Owhondah RO, Walker M, Ma L, Nimmo B, Ingham DB, Poggio D, Pourkashanian M. Assessment and parameter identification of simplified models to describe the kinetics of semi-continuous biomethane production from anaerobic digestion of green and food waste. Bioprocess Biosyst Eng. 2016;39(6):977-92.

60. Chai T, Draxler RR. Root mean square error (RMSE) or mean absolute error (MAE)?-Arguments against avoiding RMSE in the literature. Geosci Model Dev. 2014;7(3):1247-50.

61. Tsai SB, Xue Y, Zhang J, Chen Q, Liu Y, Zhou J, Dong W. Models for forecasting growth trends in renewable energy. Renew Sustain Energy Rev. 2017:77:1169-78.

62. Hamawand I, Baillie C. Anaerobic digestion and biogas potential: simulation of lab and industrial-scale processes. Energies. 2015;8(1):454-74.

63. Angelidaki I, Ellegaard L, Ahring BK. A mathematical model for dynamic simulation of anaerobic digestion of complex substrates: focusing on ammonia inhibition. Biotechnol Bioeng. 1993;42(2):159-66.

64. Angelidaki I, Ellegaard L, Ahring BK. A comprehensive model of anaerobic bioconversion of complex substrates to biogas. Biotechnol Bioeng. 1999;63(3):363-72.

65. Kovalovszki A, Alvarado-Morales M, Fotidis IA, Angelidaki I. A systematic methodology to extend the applicability of a bioconversion model for the simulation of various co-digestion scenarios. Bioresour Technol. 2017;235:157-66

66. Lovato G, Alvarado-Morales M, Kovalovszki A, Peprah M, Kougias PG, Rodrigues JAD, Angelidaki I. In-situ biogas upgrading process: modeling and simulations aspects. Bioresour Technol. 2017;245:332-41.

67. Xiao KK, Guo CH, Zhou Y, Maspolim Y, Wang JY, Ng WJ. Acetic acid inhibition on methanogens in a two-phase anaerobic process. Biochem Eng J. 2013;75:1-7.

68. Doloman A, Varghese H, Miller CD, Flann NS. Modeling de novo granulation of anaerobic sludge. BMC Syst Biol. 2017;11(1):69.

69. Jiang J, Wu J, Poncin S, Li HZ. Effect of hydrodynamic shear on biogas production and granule characteristics in a continuous stirred tank reactor. Process Biochem. 2016;51(3):345-51.

70. Mawson AJ, Earle RL, Larsen VF. Degradation of acetic and propionic acids in the methane fermentation. Water Res. 1991;25(12):1549-54.

71. Mussati MC, Fuentes M, Aguirre PA, Scenna NJ. A steady-state module for modeling anaerobic biofilm reactors. Lat Am Appl Res. 2005;35(4):255-63.

72. Demitry ME. Anaerobic digestion process stability and the extension of the ADM1 for municipal sludge co-digested with bakery waste. PhD dissertation. 2016

73. Demitry ME, Zhong J, Hansen C, McFarland M. Modifying the ADM1 model to predict the operation of an anaerobic digester Co-digesting municipal sludge with Bakery waste. Environ Pollut. 2015. https://doi. org/10.5539/ep.v4n4p38.
Ready to submit your research? Choose BMC and benefit from:

- fast, convenient online submission

- thorough peer review by experienced researchers in your field

- rapid publication on acceptance

- support for research data, including large and complex data types

- gold Open Access which fosters wider collaboration and increased citations

- maximum visibility for your research: over $100 \mathrm{M}$ website views per year

At $\mathrm{BMC}$, research is always in progress.

Learn more biomedcentral.com/submissions 